\title{
Enterprise Informatization Maturity Model Based on Delphi Method
}

\author{
Meiyun Zuo and Hongiiao Fu \\ Department of Economic Information Management, School of Information, Renmin \\ University of China, Beijing 100872, P.R. China zuomeiyun@263.net, fuhongiao@263.net
}

\begin{abstract}
Based on the studies of existing informatization maturity model at home and abroad, the paper puts forward a new enterprise Informatization Maturity Model. The authors collected the opinions of fifteen well-known Chinese informatization experts about the model by Delphi method. Through statistical analysis, it can be found that the extent of the experts' acceptance is very high. According to the experts' opinions pertaining to the model, the authors get an amended five-stage Informatization Maturity Model which consists of technology support level, resources integration level, management optimization level, strategy support level and sustained improvement level.
\end{abstract}

Keywords: Enterprise information systems, Informatization maturity model, Maturity, Model, Informatization

\section{INTRODUCTION}

At present enterprises are puzzled about some issues in conducting informatization: Where should I start informatization? Which stage of informatization is our organization at? Whether there is an end of informatization road? The purpose of this research is trying to solve above questions and get a general Informatization Maturity Model (IMM).Using IMM can not only instruct enterprises conducting the construction of informatization, but also can objectively evaluate their informatization level. Furthermore, IMM can be used in evaluation of informatization level for one company by itself or by the third parts such as relevant government departments.

IMM should have following functions: 1) guiding function: helping enterprises to accurately understand the aims of informatization, conduct informatization planning and level evaluation, and achieve the goal of informatization; 2) inspiring function: inspiring organization to pursuit higher maturity. Acquiring a higher level is a kind of honor to enterprises; 3) service function: supporting government administrator to understand the status of local enterprises' informatization, and improve the decision making on informatization policies.

The rest of this paper is organized as follows. Section 2 reviews relevant literature and develop a new informatization maturity model (IMM). Section 3 describes the research method used in this study. Section 4 reports the main findings of our data analysis, which is followed by Section 5 describing the enhancement IMM model. Section 6 gives some limitations in this paper and some future works for authors.

Please use the following format when citing this chapter:

Zuo, M., Fu, H., 2007, in IFIP International Federation for Information Processing, Volume 255, Research and Practical Issues of Enterprise Information Systems II Volume 2, eds. L. Xu, Tjoa A., Chaudhry S. (Boston: Springer), pp. 1117. 1126. 


\section{LITERATURE REVIEW AND DEVELOPMENT OF A NEW MODEL}

\subsection{Relevant Literature}

The research on a general Informatization Maturity Model is about the evolution rule of enterprise informatization from immature to mature stage. Enterprise informatization is an issue of evolution with different levels. Since 1960s, in the research on information system, the topic of informatization growth process has been attracted extensive attention of academia and industrial fields.

To date, the common models describing enterprise informatization stages include: Nolan Model [1-4], Synnott Model [5-6], Mische Model [7], Hanna Model [8], Edgar Schein Model [9], SW-CMM [10], IT Process Maturity Model under COBIT [11], Technology-Information Maturity Model [12], Business-IT Strategic Alliance Maturity Model [13], Value Chain-based Four-stage Model [14] etc.

After analysis on above ten models, we find the description of models can be classified into two types: step-style model and radar-style model; designing thought can be concluded into two methods and four dimensions. As shown in Table 1.

According to the fundamental element of information system, there are two modeling dimensions, i.e. 'information technology (IT) 'and 'information resources (IR)'; on the other hand, according to the function of informatization, there are also two modeling dimensions, i.e. 'lateral value chain (LVC)' and 'vertical management chain (VMC)'. In this paper, IT refers to the information technologies applied in enterprises; IR refers to requirements of information from business and management aspects; LVC means the process of business from single department to across department, and from interior to exterior of enterprises; VMC refers to the management chain of grass-roots operation, middle-level management and high-level decision making.

Through analysis on above enterprise informatization models, we find out those above models embodied the informatization rules under certain historical condition. As anybody can see, current network era is unprecedented. For instance, previous enterprise informatization stage model seldom took security and risk issues of information systems into consideration. Therefore, we think a new model needs to be designed to evaluate current maturity of enterprise informatization.

\subsection{Development of the General Informatization Maturity Model}

According to the comparison in Table 1, we know that current models are mainly evaluated by four aspects which are IT, IR, LVC, VMC. Among them, IT and IR are two fundamental elements of information systems; while LVC and VMC are presented from two kinds of application demands. According to the comparison of ten old models, we find the focus of enterprise informatization is on from only IT to the integration of IT and IR, from operation management to decision support, from single 
department to the whole supply chain management, in other words, emphasizing the informatization of LVC and VMC. In order to develop a general Informatization Maturity Model based on current environment, we integrated these four aspects according to stage thinking reflected by step-style model and multidimensional thinking reflected by radar-style model.

Table 1. Comparison between Common Informatization Maturity Models

\begin{tabular}{|c|c|c|}
\hline Model & $\begin{array}{l}\text { Modeling } \\
\text { Dimension }\end{array}$ & Main Perspective \\
\hline Nolan Model & IT & $\begin{array}{l}\text { Emphasizing the scale of IT } \\
\text { application and the state of investment } \\
\text { on IT }\end{array}$ \\
\hline Synnott Model & IR & $\begin{array}{l}\text { Emphasizing effective allocation of } \\
\text { information resources and the role of } \\
\text { Chief Information Officer }\end{array}$ \\
\hline Mische Model & $\begin{array}{l}\text { Integration of IT } \\
\text { and IR }\end{array}$ & $\begin{array}{l}\text { Emphasizing indivisibility between } \\
\text { information system integration and data } \\
\text { management }\end{array}$ \\
\hline Hanna Model & $\mathrm{VMC}$ & $\begin{array}{l}\text { Emphasizing the improvement of } \\
\text { core competitive capacity by } \\
\text { informatization. }\end{array}$ \\
\hline $\begin{array}{l}\text { Edgar Schein } \\
\text { Model }\end{array}$ & IT & $\begin{array}{l}\text { Emphasizing serious analysis and } \\
\text { long-term thinking to the adoption of IT. }\end{array}$ \\
\hline SW-CMM Model & IT & $\begin{array}{l}\text { Emphasizing the ability of software } \\
\text { enterprises and developers }\end{array}$ \\
\hline $\begin{array}{l}\text { TT Process } \\
\text { Maturity Model under } \\
\text { COBIT }\end{array}$ & IT & $\begin{array}{l}\text { Emphasizing the ability of client } \\
\text { enterprises and users }\end{array}$ \\
\hline $\begin{array}{l}\text { Technology- } \\
\text { Information Maturity } \\
\text { Model }\end{array}$ & $\begin{array}{l}\text { Integration of IT } \\
\text { and IR }\end{array}$ & $\begin{array}{l}\text { Emphasizing innovations and } \\
\text { improvement of enterprise performance } \\
\text { by using IT }\end{array}$ \\
\hline $\begin{array}{l}\quad \text { Business-IT } \\
\text { Strategic Alliance } \\
\text { Maturity Model }\end{array}$ & $\begin{array}{l}\text { Integration of IT } \\
\text { and IR, Integration of } \\
\text { LVC and VMC. }\end{array}$ & $\begin{array}{l}\text { Emphasizing the coordination of IT } \\
\text { and business, and the combination of } \\
\text { informatization and organization } \\
\text { strategy goal }\end{array}$ \\
\hline $\begin{array}{l}\text { Value Chain- } \\
\text { based Four-stage } \\
\text { Model }\end{array}$ & $\begin{array}{l}\text { Lateral Value } \\
\text { Chain }\end{array}$ & $\begin{array}{l}\text { Emphasizing the implementation of } \\
\text { informatization from single department } \\
\text { to across department, from interior to } \\
\text { exterior of organizations. }\end{array}$ \\
\hline
\end{tabular}

On the basis of above rationale, we put forward a general Informatization Maturity Model (IMM) after five rounds' discussion within our research team. As shown in Table 2.

We divided the IMM model into five levels, each of which contains several key features. What we must to stress is that this model is not a procedure that an enterprise must implement step by step. That is to say, an enterprise can aim at the status of the third or the fourth or fifth level to make informatization strategy and planning, needless to implement from the first level at all. IMM model just embodies the status of achievements through enterprise informatization construction, which is helpful for 
enterprises to understand their level of informatization maturity. Next we give the description of every level of this model separately.

Table 2. A General Enterprise Informatization Maturity Model (IMM)

\begin{tabular}{|c|c|c|c|}
\hline Level & $\begin{array}{c}\text { Name } \\
\text { of Level }\end{array}$ & $\begin{array}{l}\text { Content } \\
\text { Concerned }\end{array}$ & Key Status \\
\hline First & $\begin{array}{l}\text { Technology } \\
\text { Support } \\
\text { Level }\end{array}$ & IT & $\begin{array}{l}\text { 1.1 IT Infrastructure } \\
\text { 1.2 Files Electronization } \\
1.3 \text { Independent Information Systems }\end{array}$ \\
\hline Second & $\begin{array}{l}\text { Resources } \\
\text { Integration } \\
\text { Level }\end{array}$ & IT and IR & $\begin{array}{l}\text { 2.1 Local Area Network Construction } \\
\text { 2.2 Database Planning } \\
\text { 2.3 Business Efficiency }\end{array}$ \\
\hline Third & $\begin{array}{l}\text { Management } \\
\text { Optimization } \\
\text { Level }\end{array}$ & $\begin{array}{l}\text { IT and IR; } \\
\text { VMC and } \\
\text { internal LVC }\end{array}$ & $\begin{array}{l}\text { 3.1 Informatization Environment of } \\
\text { Enterprise } \\
\text { 3.2 Business Processing Optimization } \\
\text { 3.3 Business Benefit }\end{array}$ \\
\hline Fourth & $\begin{array}{l}\text { Strategy } \\
\text { Support } \\
\text { Level }\end{array}$ & $\begin{array}{l}\text { IT and IR; } \\
\text { VMC and LVC }\end{array}$ & $\begin{array}{l}\text { 4.1 Information Strategy } \\
\text { 4.2 Core Competence } \\
\text { 4.3 Decision Supporting } \\
\text { 4.4 Supply Chain Management } \\
\end{array}$ \\
\hline Fifth & $\begin{array}{l}\text { Sustained } \\
\text { Improvement } \\
\text { Level. }\end{array}$ & $\begin{array}{l}\text { IT and IR; } \\
\text { VMC and LVC }\end{array}$ & $\begin{array}{ll}\text { 5.1 } & \text { Learning Organization } \\
5.2 & \text { Information Mechanism } \\
5.3 & \text { Innovations Management }\end{array}$ \\
\hline
\end{tabular}

The first level, i.e. IMM1, is technology support level. It is the lowest level of IMM model, which is presented from the perspective of information technology. Only when an enterprise reaches this level, does it really start to step into the door of enterprise informatization. In this level, the enterprises mainly purchase IT equipments like computers, develop business-oriented application systems, and basically realize electronization of files transmitted within the organization. There are independent systems and databases in some departments, but they might not be compatible and information islets might exist. Furthermore, there is distinct shortage on the aspects of effectively using information resources, supporting management, and assisting strategy, etc.

The second level, i.e. IMM2, is resources integration level, which not only keeps eyes on information technology, but also focuses on information resources in organizations. An enterprise which reaches this level begins to consider information as a kind of resources and make the planning of information resources in the organization. These enterprises take improving organization whole operation efficiency as their objective, LAN construction, data integration as their focus of investment, to realize information sharing and information islets eliminating. In this level, information technology brings about the improvement of operation efficiency, but the benefit of informatization still not emerged out. 
The third level, i.e. IMM3, is management optimization level, which mainly takes vertical management chain and lateral value chain within organization into consideration. Normally, an enterprise which reaches this level stresses the construction of enterprise informatization environment, for example, assigns a position of CIO. On the basis of resources integration, it truly combines information technology investment and management mode, by conducting business process reengineering or business process improvement [15]. After improving entire operating efficiency, enterprises turn to the pursuit of the actual business benefit.

The fourth level, i.e. IMM4, is strategy support level developed from the perspective of vertical management chain and lateral value chain. This level stresses on high-level decision supported and integration of internal and external business process of organization. An enterprise which reaches this level has planned the information strategy to make it consistent with business strategy. Enterprises start to integrate all kind of resources with their all kinds of partners. By informatization of core value chain, enterprises strengthen themselves core competence.

The fifth level, i.e. IMM5, is sustained improvement level. It is the highest level of IMM model, which embodies itself an open model. An enterprise which reaches this level has been a learning organization, has owned the mechanisms of IT governance, and tries to become an innovative organization. Informatization has already been fundamental and vital, just like electricity existing everywhere, which makes people feel that it is not important anymore.

\section{RESEARCH METHODOLOGY}

\subsection{Delphi Method}

Delphi method is in fact a kind of anonymous inquiring method. Delphi method uses anonymous way to inquire opinions of experts and impel back-to-back communication between experts, which can fully utilize experts' knowledge and experience, at last to get a result that can reflect collective will. It has characteristics of anonymousness, feedback, and statistic, etc. If the opinions of experts are relatively scattering, the process of anonymous inquiring may be made for many rounds until opinions of experts reach the agreement in the meaning of statistics.

\subsection{Selection of Experts}

After drafted an IMM shown as table 2, we selected thirty well-known Chinese informatization experts who have been engaged in research relating informatization area at least for ten years. We followed an investigation on fifteen experts who like to participate in this investigation. After the return of investigation result, according to the opinions of experts and their scoring result to index system, we did some modification on IMM model appropriately. 


\subsection{Design of Questionnaire}

Our questionnaire consists of two parts: one is a survey of level names; another is a survey of key features of each level. Questionnaire mainly used to investigate the rationality of naming normalization, independence, hierarchy and guiding of every level's name used in IMM model in Table 2, and evaluation of importance, independence and general adaptation of key features in every level. The questionnaire adopted the form of general Likert scales, but there is a little difference. Scoring system of each index is four-point method with an interval of 0.1 from 0 to 4 , for example, the score could be $2.1,3.8$, etc. The lowest score is zero and the highest is four.

Among them, naming normalization is used to examine if the level's name is defined normatively and clearly; while independence is used to examine if each level or each key feature needs to be set up independently; hierarchy is used to examine if there exists a span between two conjoint levels and the spaces of those span are roughly the same; guiding is used to examine if each level and its description have the guiding function to enterprise informatization; importance is used to examine the degree of each key feature' importance in corresponding level; general adaptation is used to examine the universal adaptation degree of each feature in different enterprises.

\section{DATA ANALYSIS}

In the following analysis, we use SPSS as our statistic tool. We mainly use some quantitative analysis methods, such as reliability analysis, descriptive statistics, etc.

\subsection{Reliability Analysis of Questionnaire}

Reliability refers to the probability of getting the same research result when using same research technology to measure the same object repetitively. Reliability reflects consistency and stability of survey result. Here we adopted Cronbach's $\alpha$ to analyze the questionnaire. When the value of Cronbach's $\alpha$ is between 0.7 and 0.9 , it means a high reliability; when above 0.9 , it means a very high reliability. Data analysis shows that, besides coefficients $\alpha$ of two indices are 0.873 and 0.8597 , others are all above 0.9 . Obviously, our questionnaire has very high reliability.

\subsection{Descriptive Statistics}

Descriptive statistics were made on four evaluation indices of every level and three evaluation indices of every key feature. Through three statistical values of mean, median and mode, we can find experts' whole evaluation of each index on every level name. The higher values of the mean, median and mode, means the higher consensus evaluation that experts gave to the level name. Through two statistical values of experts' scoring span and $95 \%$ confidence interval of average score, we can tell the 
consistency extent of experts' opinion. The smaller experts' scoring span and $95 \%$ confidence interval of average score, the closer experts' opinions are.

As the statistic results we got by SPSS software shown (For the limitation of the requirement length of this paper, the data analysis of an index is shown in Table 3 as an example), the means of four indices of level names are all above 3.1, most median are about 3.5, and the modes are generally 3 or 4 , so it can be inferred that the experts approbatory evaluation on level names is very high. Among them, evaluation score of hierarchy indices is very high, which means the span of every level in IMM model has certain rationality. The interval of scores given by experts is mostly within 2 and 4 ; the spans of scores are mostly 2 ; and almost all lengths of $95 \%$ confidence interval of all indices are under 0.5 . These results suggest that experts' opinions are quite consistent generally. Certainly, there still exist seldom big differences on specific indices of specific level names.

Table 3. Statistic Description of Naming Normalization of Level Name

\begin{tabular}{|c|c|c|c|c|c|c|}
\hline \multicolumn{2}{|c|}{ Level Name } & IMM1 & IMM2 & IMM3 & IMM4 & IMM5 \\
\hline \multicolumn{2}{|c|}{ Mean } & 3.167 & 3.24 & 3.273 & 3.4 & 3.307 \\
\hline \multicolumn{2}{|c|}{ Median } & 3 & 3 & 3.5 & 3.3 & 3.5 \\
\hline \multicolumn{2}{|c|}{ Mode } & 3 & 3 & 4 & 3 & 3.5 \\
\hline \multicolumn{2}{|c|}{ Sample Variance } & 0.69 & 0.437 & 0.556 & 0.24 & 0.409 \\
\hline \multicolumn{2}{|c|}{ Scoring Span } & 2.5 & 2 & 2 & 1.5 & 2 \\
\hline \multicolumn{2}{|c|}{ Lowest Score } & 1.5 & 2 & 2 & 2.5 & 2 \\
\hline \multicolumn{2}{|c|}{ Highest Score } & 4 & 4 & 4 & 4 & 4 \\
\hline \multirow{2}{*}{$\begin{array}{c}\quad 95 \% \\
\text { Confidence } \\
\text { Interval of } \\
\text { Average } \\
\text { Score }\end{array}$} & Lower & 2.707 & 2.874 & 2.86 & 3.129 & 2.952 \\
\hline & Upper & 3.627 & 3.606 & 3.686 & 3.671 & 3.661 \\
\hline
\end{tabular}

From the results of data analysis, we also know the means of three indices of key features are all above 3.1, most medians are above 3.5, and the modes are generally 4 , so the experts' evaluation scores on key features are very high. Among them, evaluation scores of importance and general adaptation indices are very high, which means the content design of IMM model has certain rationality. While evaluation scores of independence are relatively low, this means that selection of features of IMM model need to be adjusted to some extent.

From analysis of descriptive statistics on level names and key features, it can be seen that the extent of the experts' acceptance to the IMM model is very high. Meanwhile, it shows that IMM model receives basic approve of experts. 


\section{DESCRIPTION OF THE ENHANCEMENT MODEL}

According to the results based on above statistical analysis and experts' concrete written opinions in questionnaires, we did appropriate revision and enhancement on IMM model and got enterprise informatization maturity step-style model illustrated in Figure 1. The key features of each level were adjusted appropriately in detail. Next we give the description of the model revision separately.

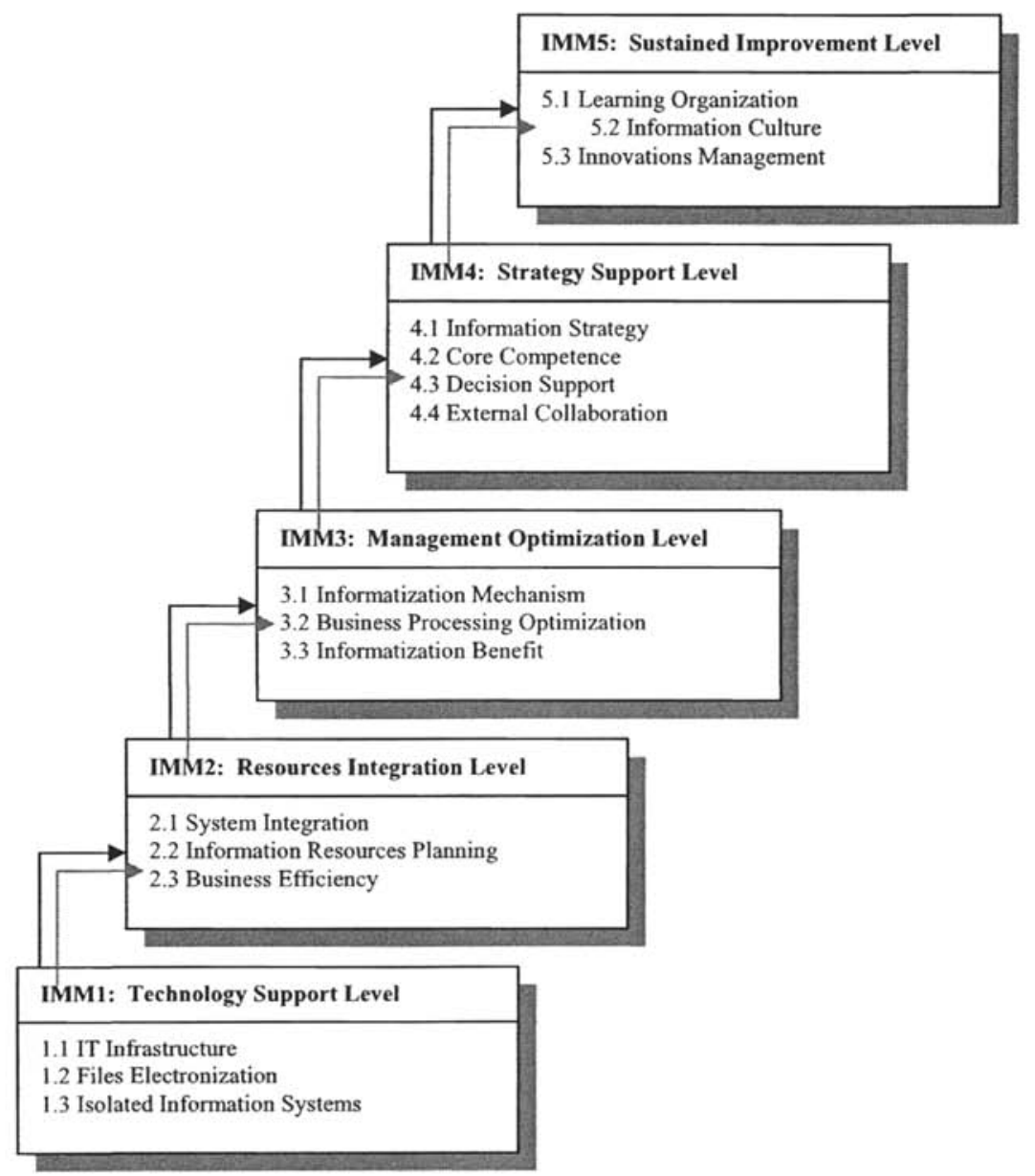

Figure 1. Enterprise Informatization Maturity Model（IMM）after Revision

In the IMM1 stage, we revised "1.3 Independent Information Systems" to "1.3 Isolated Information Systems", which aims to emphasize that the systems can't communicate with each other. 
In the IMM2 stage, "2.1 Local Area Network Construction" was revised to "2.1 System Integration", in order to stress on the integration of isolated systems. " 2.2 Database Planning" was revised to " 2.2 Information Resources Planning", for the sake of standing out the importance of information resources planning.

In the IMM3 stage, we revised "3.1 Informatization Environment of Enterprise" to "3.1 Informatization Mechanism", since an enterprise which reaches this middle level can't develop good information environment such as information culture yet, however, can build the informatization mechanism, for example, assigned a position of Chief Information Officer (CIO) . Moreover, we revised " 3.3 Business Benefit" to "3.3 Informatization Benefit", because some experts argued not all benefits are produced by informatization construction, the informatization benefit should be separated to consideration.

In the IMM4 stage, "4.4 Supply Chain Management" was revised to "4.4 External Collaboration", in order to stress on the all-flow-in-one, which means data flow, capital flow, material flow, and business flow can contact well with each other in all partners.

In the IMM5 stage, we revised " 5.2 Information Mechanism" to " 5.2 Information Culture", the reason is the enterprise reaching this level must positively push forward the cultivation process of information culture and make great efforts to make informatization goal immersing in actual activities of every staff.

After above enhancement, we organized a formal meeting to review the revision model, the experts attending the meeting gave the high approval to this new one.

What we want to declare is that above IMM model is used to evaluate current informatization state of an enterprise, not to show the procedure or route that an organization should go through for its informatization. In fact, informatization of an enterprise should make a whole planning by aiming at the goal of fourth or fifth level, and then implement it step by step.

\section{LIMITATIONS AND FUTURE WORKS}

The main limitation of the paper is that the IMM model is a theoretical model, which is just tested by experts and needs to be verified in practice in the future. In order to use this IMM model to evaluate enterprise's informatization state, we will develop an entire set of evaluation index system in our future works.

In addition, enterprises belong to different industries. Although what we discussed is a general model, but some industry features will more or less affect the meaning explanation of key features of each level. We need to deepen this point in our followup research.

\section{ACKNOWLEDGEMENTS}

This research was supported by a research grant from the Foundation of Key Laboratory of Information Management and Information Economics (Project No. 
F0607-42) and by a special grant from the Fok Ying-Tung Education Foundation to the first author.

\section{REFERENCES}

1. C.F. Gibson and R.L. Nolan, Managing the Four Stages of EDP Growth, Harvard Business Review. Volume 52, Number 1, pp.76-88, (1974).

2. R.L. Nolan, Managing the Computer Resource: A Stage Hypothesis, Communications of $A C M$. Volume16, Number 7, pp.399-405, (1973).

3. R.L. Nolan, D.C. Croson, and K.N. Seger, The Stages theory: A Framework for IT Adoption and Organizational Learning (Harvard Business School Publishing: Boston, Massachusetts, 1993).

4. R.L. Nolan, Managing the Crisis in Data Processing, Harvard Business Review. Volume 527, Number 2, pp.115-126, (1979).

5. W.R. Synnott, The Information Weapon: Winning Customers and Market with Technology (Wiley Publishing: New York, 1987).

6. W.R. Synnott and W.H. Gruber, Information Resource Management: Opportunities and Strategies for the 1980s (Wiley Publishing: New York, 1981).

7. J. Wyzalek, Reengineering: System Integration Success (Auerbach Publishers: Boston, Massachusetts, 1998).

8. N. Hanna, Information Strategy and Information Technology Diffusion, translated by X.Y. Dong (China Translation \& Publishing Corporation: Beijing, 2000).

9. J.P. Wu, K. Xie, and M.M. Wang, Information Economics (Higher Education Press: Beijing, 2002).

10. M.C. Paulk, Capability Maturity Model for Software Version (Technical Report of Software Engineering Institute, Carnegie Melon University: Pittsburgh, 1988).

11. W. John and I.V. Lainhart, COBIT TM: A Methodology for Managing and Controlling Information and Information Technology Risks and Vulnerabilities, Journal of Information Systems. Volume 14, Number 1, pp.21-25, (2000).

12. S. Dutta and J.F. Manzoni, Process Re-engineering, Organizational Change and Performance Improvement (McGraw-Hill Companies: New York, 2001).

13. J.N. Luftman, Assessing Business-IT Alignment Maturity, Communications of the Association for Information Systems. Volume 4, Number 14, pp.1-51, (2000).

14. J.W. Murry and J.O. Hammons, Delphi: A Versatile Methodology for Conducting Qualitative Research, The Review of Higher Education. Volume 18, Number 4, pp.423436, (1995).

15. C. MØller, Process innovation laboratory: a new approach to business process innovation based on enterprise information systems, Enterprise Information Systems. Volume 1, Number 1, pp.113-128, (2007). 